D. Y. YOO, A, D, HAUSER, S. T, JOY, D, BAR-SAGI*,P, S, ARORA* (NEW YORK

UNIVERSITY AND NEW YORK UNIVERSITY SCHOOL OF MEDICINE, USA)

Covalent Targeting of Ras G12C by Rationally Designed Peptidomimetics

ACS Chem. Biol. 2020, 15, 1604-1612.

\title{
Covalent Inhibition of Ras G12C with a Stapled Peptidomimetic
}
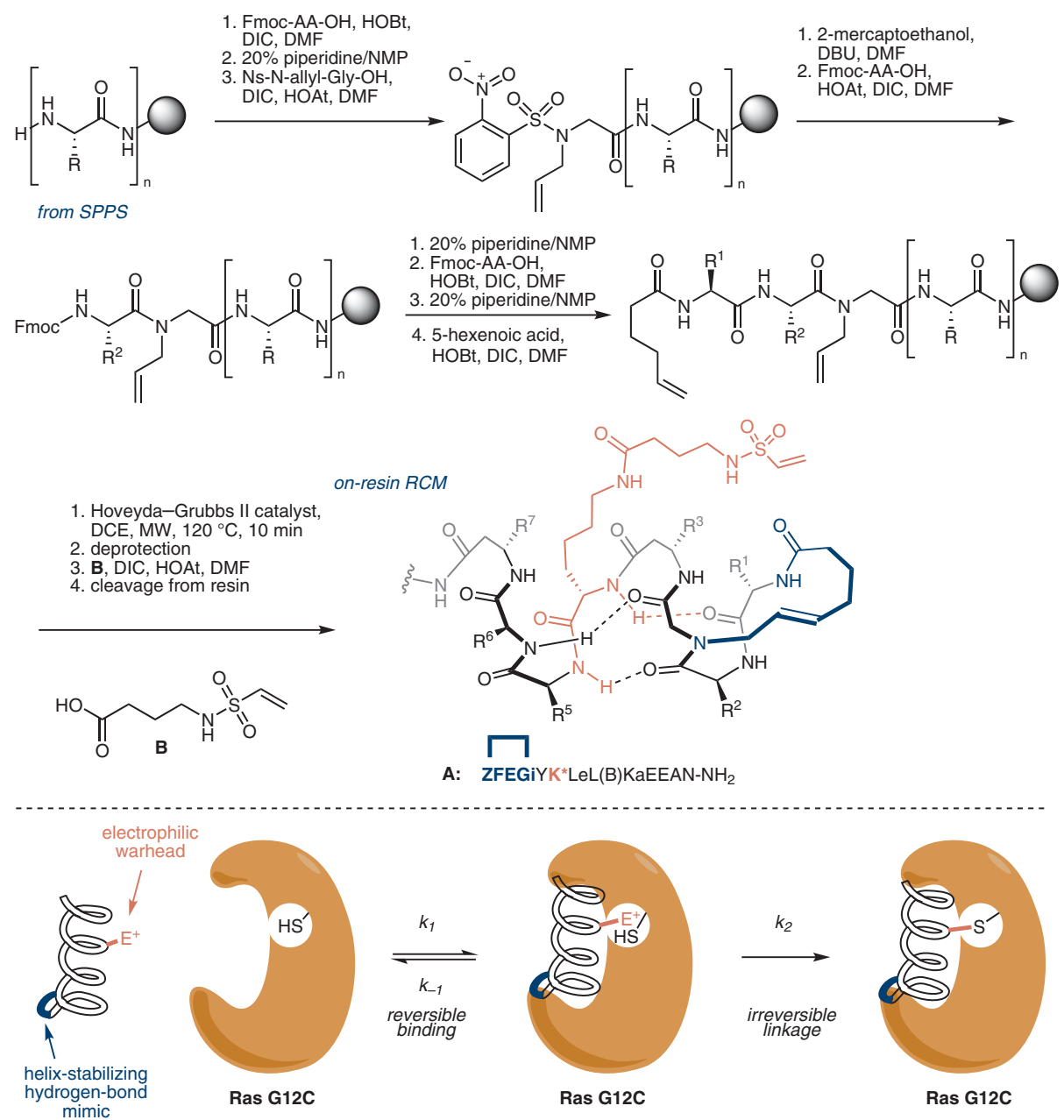

Significance: Ras proteins are central to several pathways involved in cell proliferation and survival. Dysregulation in Ras signaling is implicated in nearly $30 \%$ of all human tumors, and therefore represents an important target in oncology. Bar-Sagi, Arora, and co-workers describe the development of a covalent inhibitor of mutant Ras G12C, using a stapled peptidomimetic scaffold based on the nucleotide exchange factor Son of Sevenless (SoS).
Comment: Inhibitor A was synthesized using SPPS and includes an interesting hydrogen-bond surrogate (HBS) motif that is generated from an on-resin ring-closing metathesis of an internal $\mathrm{N}$-allyl glycine to an $\mathrm{N}$-terminal hexenoic amide. Binding of $\mathbf{A}$ to Ras $\mathrm{G} 12 \mathrm{C}$ triggers proximity-induced cysteine alkylation of A's sulfonamide motif. Biochemical assays indicate that the $\mathrm{G} 12 \mathrm{C}$ mutation is necessary for Ras inhibition and modulation of downstream effects by $\mathbf{A}$.

\section{Key words}

Ras inhibitors

covalent inhibitors

peptidomimetics

stapled peptides

oncology 